\title{
Prevalence of hearing loss in children following bacterial meningitis in a tertiary referral hospital
}

Benson Wahome Karanja ${ }^{1 *}$, Herbert Ouma Oburra ${ }^{2}$, Peter Masinde ${ }^{3}$ and Dalton Wamalwa ${ }^{4}$

\begin{abstract}
Background: This study aimed to examine hearing function in a group of children aged between the ages of six months and twelve years admitted with bacterial meningitis so as to determine the prevalence and degree of sensorineural hearing loss in them. This prospective study was conducted in the audiology unit and paediatric wards of Kenyatta National Hospital, KNH.

Methods: The study involved 83 children (49 males and 34 females) between the ages of six months and twelve years admitted with bacterial meningitis. The median age for the children examined was 14 months (range from 5 to 120 months). They were sequentially recruited and at discharge following treatment, underwent age-appropriate hearing testing to evaluate presence and degree of hearing loss which was analyzed. The study was limited by the absence of otoacoustic emission and auditory brainstem responses testing by excluding the significant numbers of children below six months of age admitted with bacterial meningitis.
\end{abstract}

Results: Thirty six of the 83 children (44.4\%) were found to have at least a unilateral mild sensorineural hearing loss during initial audiologic testing. Of the children with hearing loss, 22 (26.5\%) had mild or moderate sensorineural hearing loss and 14 (16.9\%) had severe or profound sensorineural hearing loss.

Conclusions: Sensorineural hearing loss was shown to be highly prevalent in children treated for bacterial meningitis. There is therefore a need for objective hearing assessment in infants and young children following bacterial meningitis and further studies involving larger population sizes.

Keywords: Hearing tests, Kenyatta national hospital, Sensorineural hearing loss (SNHL), Coma score, Seizures, Cranial nerve neuropathy, Positive CSF culture, Fever

\section{Background}

Deafness is one of the commonest serious complications of bacterial meningitis in childhood. In developed countries, approximately $10 \%$ of survivors of bacterial meningitis are left with permanent sensorineural hearing loss [1-3]. Other children experience a transient hearing loss [3-6]. Both types of hearing impairment are thought to develop during the first few days of the illness [5-7].

Kenyatta National Hospital, KNH is Kenya's national referral hospital. Estimates show that an average forty five children are admitted into its pediatric wards each month with a confirmed diagnosis of bacterial meningitis.

Behavioral tests of hearing may be used when an infant reaches the developmental age (as opposed to the

\footnotetext{
* Correspondence: drwahome@iconnect.co.ke

${ }^{1}$ University of Nairobi, P.O. Box 2209-00202, KNH, Nairobi, Kenya

Full list of author information is available at the end of the article
}

chronological age) of six months. Infants not at this level of development and some of those with more than one disability will need to be tested by otoacoustic emissions (OAEs) and auditory brainstem responses (ABRs). Unfortunately the equipment for these latter two sets was unavailable forcing the study to be carried out in children above 6 months of age using behavioural of distraction testing.

So far, in KNH no similar study had been undertaken to determine the prevalence and burden of hearing loss following bacterial meningitis in children admitted to $\mathrm{KNH}$.

\section{Methods}

\section{Participants}

The study involved 83 children (49 males and 34 females) between the ages of six months and twelve years admitted with bacterial meningitis from the pediatric wards, $\mathrm{KNH}$. All cases admitted within twenty four hours of diagnosis,

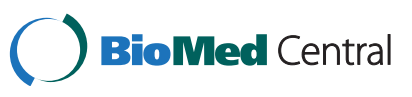


who met the inclusion criteria were recruited every weekday evening during the 3-month study period.

The lack of ABR and OAE testing limited the present study to behavioral tests of hearing which may only be used when an infant reaches the developmental age (as opposed to the chronological age) of six months.

All participants fulfilled the following criteria: age six months or older at the time of admission and confirmed diagnosis of bacterial meningitis. Bacterial meningitis was defined according to the World Health Organization (WHO) workbook recommendations based on laboratory findings, symptoms or signs [8]. Those excluded from the study included all with a confirmed diagnosis of or on current treatment for tuberculosis; prior history of hearing loss; using ototoxic antibiotics as part of treatment; chronic medical conditions (diabetes, renal, cardiac diseases); on treatment for malaria. Besides antibiotics all the patients received intravenous dexamethasone $(0.6 \mathrm{mg} / \mathrm{kg}$ per day in four divided doses). The first dose of dexamethasone was administered 10-15 minutes before administration of antibiotic and was continued for four days.

A full medical history was documented and factors relating to the patient and prior treatment documented by the principal investigator in the questionnaire. The history included parental or a guardians' assessment of hearing and any history of ear discharge or infection. Otoscopy was done using a Riester hand-held otoscope and its aural speculums and the findings recorded. The children then underwent a thorough physical examination. Hematological and CSF study results were documented. All these were entered in the patient's proforma.

A full physical examination and hearing assessment was done prior to discharge from hospital and two weeks after. This identified and excluded transient hearing loss.

All participants' parents or guardians gave informed consent for the study. Five guardians declined to have their children involved in the study. The study was approved by the institutional ethics and review committee of $\mathrm{KNH}$.

\section{Audiological protocol}

All patients completed age-appropriate hearing tests carried out by trained audiologists in the ENT audiology section in a sound- proofed booth. This was well- lit with minimal littering to minimize the child's distraction. The standard ambient noise was $35 \mathrm{~dB}$. It was also well ventilated and large enough to accommodate the child and parent/ guardian, tester and distractor.

Children between six and twenty four months of age underwent the distraction test, those between twenty four and thirty six months of age had the performance tests done while pure tone audiometry was carried out on children above thirty six months of age. They were carried out in the following manner:

\section{Behavioral testing} The behavioral testing equipment included toys that were not too bright used by the distractor in the behavioral tests to distract the child being examined. Three warblers were used: low, mid and high frequency types. A Manchester rattle was also used to deliver high frequency sounds during behavioral testing. The G-chime was used for midfrequency sounds and the $\mathrm{C}$-chime for high frequency sound generation.

\section{a. Distraction Test}

A distraction test was performed if the infant was sitting and able to turn and locate the source of a sound. It was carried out with the infant sat upon an adult's knee facing forwards where a distractor controlled the infant's attention using toys. The tester introduced the sound signals at high, mid and moderate frequencies from 45 degrees and one meter behind, at the level of the ear. These were tested separately in order to detect hearing loss restricted to one part of the frequency range. The sounds were introduced at very quiet levels (35dBA). Care was taken not to give clues as to the tester's position other than the test signal.

b. Performance Tests The child was shown how to wait until a sound was heard before carrying out an action. Once this could be done the test was be performed at a meter distance and from behind. The test was performed using "Go" for low frequencies, "S" for high frequencies, introduced at the quietest voice levels or 2 Warble tones at $500 \mathrm{~Hz}, 1$ or $2 \mathrm{kHz}$ and $4 \mathrm{kHz}$ introduced at a very quiet level corresponding to normal hearing. The child was said to have "passed" the screen if there were two responses at the quietest level.

2 Pure Tone Audiometry

This was carried out in all children recruited for the study above thirty six months of age. Pure tones (20dDHearing Level, HL) were introduced using headphones and testing carried out by air conduction $(500 \mathrm{H}-4000 \mathrm{~Hz})$ and bone conduction (500-4000 Hz). Pure tone audiometry was performed using an Interacoustics clinical audiometer (Model AC33; serial no. SN735530, calibration date June 2009). Sound delivery and masking during pure tone audiometry was ensured using TDH-399 headphones. No sponsorships or competing interests were involved in these tools. 
The main outcome measure was presence or absence of sensorineural hearing loss in the children.

\section{Follow up}

If the child had made a complete recovery from meningitis, lived far from the hospital, and had no hearing loss, follow up was not done.

If the child had sequalae that required further management beyond 2 weeks, follow up was continued. For those children exhibiting hearing loss, whether conductive or sensorineural, recommendations for management and follow-up were based on specific test findings and varied accordingly.

\section{Statistical analysis}

Descriptive statistics (means for continuous variables and proportions for categorical variables) were calculated to describe the population.

The main outcome was degree of sensorineural hearing loss as measured by the age-appropriate hearing test. This had three levels of outcomes: normal, mild/moderate and severe/profound. The population proportions and the $95 \%$ confidence interval, CI were estimated for each category of outcome, using statistical methods to give more precise estimates. All categorical variables were cross tabulated with the outcome and Pearson Chi Square computed.

\section{Results}

We analyzed the outcomes of eighty three children (49 males and 34 females) admitted with bacterial meningitis during the three month study period. The median age for the children examined was 14 months (range from 5 to 120 months). This is represented along with the mean on Table 1. The characteristics of the children studied are presented in Figure 1.

A significant number of the patients enrolled developed sensorineural hearing loss as a sequalae (36/83). The overall prevalence of SNHL loss was estimated to be $43.37 \%$ (95\% CI: 33.22, 55.93). Of the children with hearing loss, $22(26.5 \%)$ had mild or moderate sensorineural hearing loss, and 14 (16.8\%) had severe or profound sensorineural hearing loss. The prevalence of specific categories of SNHL is presented in Table 2.

Only seventeen (20.5\%) of CSF specimens examined cultured any bacteria. Streptococcus pneumoniae, Haemophilus influenzae and Neisseria meningitidis were isolated in 10, 4, and 3 children respectively. There were no distinctly different clinical presentations among children with $S$ pneumoniae, $H$ influenzae and $N$ meningitidis meningitis.

Table 1 Mean and Median Age Ranges

\begin{tabular}{ll}
\hline mean (SD) & Median (range) \\
\hline $29.09(31.71)$ & $14(5-120)$ \\
\hline
\end{tabular}

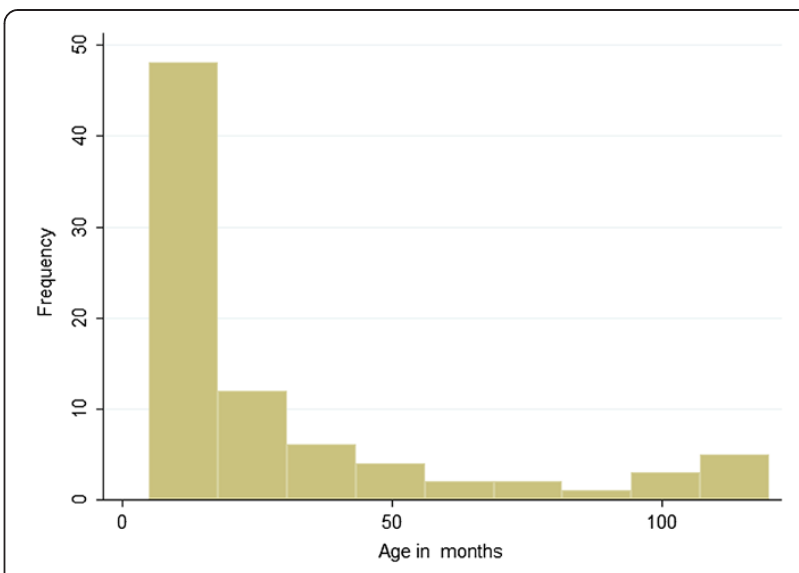

Figure 1 Age distribution in months of children evaluated.

\section{Discussion}

In the present study children proven by history and CSF findings to have bacterial meningitis were evaluated and found to have a sensorineural hearing loss prevalence following the initial hospitalization of $43.4 \%$ (95\% CI). This was therefore greater than findings of previous studies. Walter et al reported an incidence of 14\% [9] consistent with other reports $[2,4,10,11]$. This is likely due to several factors. The study institution is a tertiary referral center for a major metropolitan area that understandably receives a disproportionate number of very sick children. In addition, perhaps current pathogens are more virulent owing to continued drug-resistance. Finally, most children in this study had not had previous objective audiologic testing, and a negative history for hearing loss was based on history alone. Therefore, a few of them may have had a previously undiagnosed hearing loss despite attempts at identifying that by the principal investigator using the questionnaire. This could potentially inflate the prevalence of hearing loss; however, it is unlikely this would significantly affect the overall prevalence.

Consistent with most prior studies, this work did not reveal any relationship between occurrence and severity of hearing loss to the male gender. Forty nine (59\%) of the children evaluated were male while 34 (41\%) were female. There were no differences in the prevalence of hearing loss between the two groups. Walter et al. showed that being male was a significant independent risk factor for hearing loss [9]. Early age at illness was identified by Grimwood et al as a significant risk factor for hearing loss, with children

Table 2 Prevalence of SNHL

\begin{tabular}{lll}
\hline SHNL category & Prevalence (\%) & *Normal based 95\% Cl \\
\hline Normal & $47 / 83(56.62)$ & {$[44.79,66.05]$} \\
Mild/moderate & $22 / 83(26.51)$ & {$[17.33,35.68]$} \\
Severe/profound & $14 / 83(16.87)$ & {$[10.22,25.93]$} \\
Overall SNHL & $36 / 83(43.37)$ & {$[33.22,55.93]$} \\
\hline
\end{tabular}


suffering meningitis before twelve months of age performing more poorly than children suffering meningitis later in infancy and childhood, and age-matched controls, on measures of language and reading skills [12]. However, we found that neither age nor sex affected hearing outcome. This is in agreement with most previously reported studies $[8,13-16]$.

\section{Conclusions}

Hearing loss is highly prevalent in children treated for bacterial meningitis in Kenyatta National Hospital with a prevalence of $43.4 \%$. Age at illness was found not to be a significant determinant of hearing loss following bacterial meningitis. There exists a need for objective hearing assessment in infants and young children following bacterial meningitis. This should be mandatory in all patients treated for bacterial meningitis.

\section{Competing interests}

No sponsorships or competing interests have been disclosed for this article.

\section{Authors' contributions}

Conceived and designed the experiments: BWK. Analysed the data: BWK. Wrote the first draft of the manuscript: BWK. Contributed to the writing of the manuscript: $\mathrm{HOO}$, DW. Agree with manuscript results and conclusions: HOO, DW, PM. Jointly developed the structure and arguments for the paper: BWK, HOO, PM. Made critical revisions and approved final version: HOO, DW. All authors reviewed and approved of the final manuscript.

\section{Acknowledgements}

We acknowledge the support of our families and entire ENT fraternity in Kenyatta National Hospital.

\section{Author details \\ 'University of Nairobi, P.O. Box 2209-00202, KNH, Nairobi, Kenya. ${ }^{2}$ Department Surgery, University of Nairobi, P. O. Box 30197-00100, GPO, Nairobi, Kenya. ${ }^{3}$ ENT Department, Kenyatta National Hospital (KNH), University of Nairobi, P.O. Box 20723-00202, Nairobi, Kenya. ${ }^{4}$ Department of Pediatrics and Child Health, University of Nairobi, P. O. Box 19676-00202, Nairobi, Kenya.}

Received: 26 March 2013 Accepted: 19 February 2014

Published: 11 March 2014

\section{References}

1. Dawson JA, Wardle R: Detection and prevalence of hearing loss in a cohort of children following serogroup B meningococcal infection. Public Health 1990, 104:99-102.

2. Fortnum HM: Hearing impairment after bacterial meningitis: a review. Arch Dis Child 1992, 67:1128-1133.

3. Baraff $L$, Lee SI, Schriger DL: Outcomes of bacterial meningitis in children: a meta-analysis. Paediatr Infect Dis 1993, 12:389-394.

4. Dodge PR, Davis H, Feigin RD, Holmes SJ, Kaplan SL, Jubelirer DP, Stechenberg BW, Hirsh SK: Prospective evaluation of hearing impairment as a sequalae of acute bacterial meningitis. N Engl J Med 1984, 311:869-874.

5. Guiscafré H, Benitez-Díaz L, Benitez-Díaz L, Martínez MC, Muñoz O: Reversible hearing loss after meningitis: prospective assessment using auditory evoked responses. Ann Otol Rhinol Laryngol 1984, 93:229-232.

6. Vienny H, Despland PA, Lütschg J, Deonna T, Dutoit-Marco ML, Gander C: Early diagnosis and evolution of deafness in childhood bacterial meningitis: a study using brainstem auditory evoked potentials. J Paediatr 1984, 73:579-586

7. Klein JO, Feigin RD, McCracken GH Jr: Report of the task force on diagnosis and management of meningitis. J Paediatr 1986, 78:S959-S982.
8. Primary health care: Report of the International Conference on Primary Health Care: Alma-Alta, USSR, 6-12 September1978, Volume Health for All Series, No. 1. Geneva: World Health Organization; 1978:34.

9. Kutz JW, Simon LM, Chennupati SK, Giannoni CM, Manolidis S: Clinical predictors for hearing loss in children with bacterial meningitis. Arch Otolaryngol Head Neck Surg 2006, 132:941-945.

10. Nadol J: Hearing loss as a sequela of meningitis. Laryngoscope 1978, 88:739-755.

11. Lebel MH, Freij BJ, Syrogiannopoulos GA, Chrane DF, Hoyt MJ, Stewart SM, Kennard BD, Olsen KD, McCracken GH Jr: Dexamethasone therapy for bacterial meningitis: results of twodouble-blind, placebo-controlled trials. N Engl J Med 1988, 319:964-971.

12. Grimwood K, Anderson VA, Bond L, Catroppa C, Hore RL, Keir EH, Nolan T, Roberton DM: Adverse outcomes of bacterial meningitis in school-agesurvivors. J Paediatr 1995, 95:646-656.

13. Chotpitayasunondh T: Bacteriological meningitis in children, aetiology and clinical features, an 11 year review of 618 cases. South East Asian J Trop Med Publ Health 1994, 25:107-115.

14. Tarlow MJ, Comis SD, Tarlow MJ, Comis SD, Osborne MP: Endotoxin induced damage to the cochlea in guinea pigs. Arch Dis Child 1991, 66:181-184

15. Palva T: Cochlear aqueduct in infants. Acta Otolaryngol 1970, 70:83-94.

16. Vienney H, Despland PA, Lütschg J, Deonna T, Dutoit-Marco ML, Gander C: Early diagnosis and evolution of deafness in childhood bacterialmeningitis: a study using brain stem auditory evoked potentials. J Paediatr 1984, 73:579-586.

doi:10.1186/1756-0500-7-138

Cite this article as: Karanja et al:: Prevalence of hearing loss in children following bacterial meningitis in a tertiary referral hospital. BMC Research Notes 2014 7:138.

\section{Submit your next manuscript to BioMed Central and take full advantage of:}

- Convenient online submission

- Thorough peer review

- No space constraints or color figure charges

- Immediate publication on acceptance

- Inclusion in PubMed, CAS, Scopus and Google Scholar

- Research which is freely available for redistribution 